\title{
Prevalence of Obesity among Infertile Women Visiting Selected Infer tility Clinic at Mangalore with a View to Develop an Informational Pamphlet
}

\author{
Shanthakumari $\mathrm{K}^{1}$, Reena Wilma Frank ${ }^{2}$, Anupama Tamrakar ${ }^{3}$, \\ ${ }^{I}$ (Professor, Dean, Yenepoya Nursing College, Yenepoya University, Mangalore, India) \\ ${ }_{2}^{2}(I I$ Year $(O B G)$ M. SC Nursing, Yenepoya Nursing College, Yenepoya University, Mangalore, India) \\ ${ }^{3}$ (Lecturer, Department of OBG Nursing, Yenepoya Nursing College, Yenepoya University, Mangalore, India)
}

\section{Introduction}

Reproduction is one of the most important biological functions for all life forms. For most couples having children is a primal need and inability to reproduce, infertility can be devastating to individuals and couples ${ }^{1}$. Infertility is a medical condition characterized by a diminished or absent ability to produce offspring. A couple may be considered infertile if, after two years of regular sexual relation, without contraception, the woman has not become pregnant (and there is no other reason, such as breastfeeding or postpartum amenorrhoea). Infertility may be primary infertility and secondary infertility. Primary infertility is infertility in a couple who have never had a child. Secondary infertility is failure to conceive following a previous pregnancy.

It is estimated that 60 to 80 million couples worldwide currently suffer from infertility ${ }^{2}$. Infertility varies across regions of the world and is estimated to affect eight to twelve percent of couples worldwide. One in every four couples in developing countries had been found to be affected by infertility ${ }^{3}$. Infertility tends to be highest in countries with high fertility rates, an occurrence termed "barrenness amid plenty ${ }^{2}$." According to a report conducted by the International Institute of Population Sciences, infertility is growing at an alarming pace, especially in the cities. Out of around 250 million individuals estimated to be attempting parenthood at any given time, 13 to 19 million couples are likely to be infertile. The national census report of the past three decades, viz 2001, 1991 and 1981, showed that infertility has risen by 50 percent in the country. Nearly 30 million couples in the country suffer from infertility, making the incidence rate 10 percent ${ }^{4}$.

Infertility may not be a threat to physical health but carries with it extremely adverse social and psychological implications for all concerned but particularly in developing countries. A review article reported that there is significant association between obesity and infertility and psychological disturbances as well as their impact on quality of life and sexual functioning in women and men $^{5}$. Since it is accepted that individuals cannot achieve health in general and reproductive health in particular without the alleviation of infertility, there is an ever-increasing need and urgency to develop simple, low-cost, and effective modalities for evaluation, treatment, and prevention of infertility, which can be applied universally ${ }^{4}$.

There are several risk factors associated with infertility and one of the major factor is obesity. There is great concern at the high prevalence and the increasing trend to obesity worldwide 6 . Obesity has been thought to be a major factor in couples' who are not able to conceive. A woman is defined as obese when her Body Mass Index (BMI) is more than $30 \mathrm{~kg} / \mathrm{m}^{2}$. With the numbers of overweight and obese people growing annually, obesity is not only linked to infertility, but also other several health problems, including diabetes, cardiovascular disease, and hypertension.

Obesity not only alters our physical appearance but also disrupts the balance of hormones and enzymes inside our body. Recent reports indicate that men and women with increased body mass index (BMI) are more likely to be infertile than those of normal weight. Statistics suggest that $70 \%$ women suffering from infertility also suffer from obesity ${ }^{7}$. Studies says that, the factors associated with infertility are advanced age, elevated body mass index, age of onset of sexual activity, prior pelvic surgeries, and presence of stress. Data also suggests that a nine kilograms increase in a man's weight may increase the chance of infertility by about ten percentages, as obese men are known to have a lower sperm count, which in turn decreases the chances of conception ${ }^{8}$. To increase the fertility rate obesity has to be reduced both in men and women.

The risks to obesity and infertility will extend from conception to gestation and then to the birth process. Fertility can be negatively affected by obesity. In women, early onset of obesity favours the development of menses irregularities, chronic oligo-anovulation and infertility in the adult age. These adverse effects of obesity are specifically evident in polycystic ovary syndrome ${ }^{9}$. According to the study, which was conducted for a period of three years, out of 300 females nearly $90 \%$ of them developed polycystic ovarian disease, infertility with morbid obesity ${ }^{10}$. Obesity in women can also increase risk of miscarriage and impair the outcomes of assisted reproductive technologies and pregnancy. Studies have shown that women who are 
overweight or obese are less likely to respond to fertility drugs. This occurs because the excessive weight obstructs the proper absorption of the fertility drugs used during treatments. Some IVF clinics refuse to treat obese patients unless they reduce their BMI ${ }^{11}$. In a recent research at the Penn State Hershey College of Medicine confirmed that obese women undergoing infertility treatments needed higher doses of infertility drugs than normal-weight or underweight women ${ }^{12}$.

Obesity is a major health issue associated with infertility and many other co-morbid conditions. Studies depict that weight-loss is extremely valuable in the management of such patients, can enhance fertility, and lead to successful full term pregnancies. It is also revealed that obesity is the one of the common problems in infertile women. Hence a woman has to get awareness on the importance of weight maintenance and its importance in infertility. This study aimed to assess the prevalence of obesity in infertile women and develop and distribute the informational pamphlet.

\subsection{Method}

\section{Methods and Materials}

A non-experimental descriptive approach with a descriptive design was adopted for this study. Total of 60 women between the age of 18-45 years attending Santhathi Infertility Clinic at Mangalore was purposefully selected.

\subsection{Materials}

Two tools were used for this study. A baseline proforma with 9 items was developed and used for the collection of demographic perfoma of the women and a standard tool developed by WHO (BMI Scale) was used to assess the obesity of the women. An informational pamphlet was developed to distribute to the women. This pamphlet included the effect of obesity in infertility and ways to improve fertility in obese women.

\subsection{Validity, Reliability of tool and Pilot study}

The content validity of the tool and the contents of informational pamphlet were established with the help of experts from related fields. BMI scale was the standard scale reliability was not calculated. Pilot study was conducted on 10 samples having the same characteristics. The data obtained was analyzed by using descriptive and inferential statistics. After conducting the pilot study, it was found that the study was feasible and researchable.

\subsection{Data collection}

Data was collected from $14^{\text {th }}$ to $17^{\text {th }}$ January 2014. Prior to the data collection, permission was obtained from the concerned authorities and the Director of infertility clinic. Informed consent from the participants was obtained. They were also assured for the confidentiality of the information. Data was collected by using the developed, pre-tested demographic perfoma and WHO Scale of BMI. Data related with demographic perfoma was collected by using interview method and data related with BMI was collected by observation method with the help of weighing scale to measure weight and inch tape to measure the height. The total time duration to collect data for each woman was ten to fifteen minutes. An informational pamphlet was distributed to the women after the data collection.

Data was analyzed using descriptive and inferential statistics with the help of SPSS 17 version. Frequency and percentage was calculated for the demographic characteristics of the women. Chi-square test was applied to calculate the association between BMI score with selected demographic. Results will be represented in tables, graphs and diagrams.

\subsection{Demographic characteristics of Women}

\section{Result}

Three fourth (80\%) were in the age group of 25 to 32 years. More than half of the women (55\%) belong to Hindu religion followed by two by Muslims (37\%). Maximum of the women (83.3\%) are Non Vegetarian. More than half (61\%) of the women had secondary school education and majority of them $(93.3 \%)$ were house wife. About half of the (46.7\%) women were in 4-6 years of marital duration and slightly more than three forth $(78.3 \%)$ of women had regular menstrual pattern. The detail information is portrayed in table 1.

\subsection{Association between obesity with selected demographic variables}

Analysis of association between the obesity and selected demographic variable and among the selected women expose that there was no significant association between the obesity and selected the variables ( $\mathrm{p}$ is $>0.05$ ). the detail result is presented in the table 2 .

Table 1. Demographic characteristics of Women 


\begin{tabular}{|c|c|c|c|}
\hline 1. No $\quad$ S & Demographic Variables & Frequency & Percentage \\
\hline 1 & $\begin{array}{l}\text { Age of the women } \\
18-24 \\
25-32 \\
33-40\end{array}$ & $\begin{array}{l}1 \\
48 \\
11\end{array}$ & $\begin{array}{l}1.7 \\
80.0 \\
18.3\end{array}$ \\
\hline 2 & $\begin{array}{l}\quad \text { Religion } \\
\text { Hindu } \\
\text { Muslim } \\
\text { Christian } \\
\end{array}$ & $\begin{array}{l}33 \\
22 \\
5\end{array}$ & $\begin{array}{l}55.0 \\
36.7 \\
8.3\end{array}$ \\
\hline 3 & $\begin{array}{l}\text { Type of food } \\
\text { Vegetarian } \\
\text { Non-vegetarian }\end{array}$ & $\begin{array}{l}10 \\
50\end{array}$ & $\begin{array}{l}16.7 \\
83.3\end{array}$ \\
\hline 4 & \begin{tabular}{l}
\multicolumn{1}{c}{ Educational Status } \\
Primary \\
Secondary \\
Undergraduate \\
Post Graduate
\end{tabular} & $\begin{array}{l}13 \\
37 \\
7 \\
3\end{array}$ & $\begin{array}{l}21.7 \\
61.7 \\
11.7 \\
5.0\end{array}$ \\
\hline 5 & $\begin{array}{l}\quad \text { Occupational status } \\
\text { House wife } \\
\text { Working }\end{array}$ & $\begin{array}{l}57 \\
3\end{array}$ & $\begin{array}{l}95.0 \\
5.0\end{array}$ \\
\hline 6 & $\begin{array}{l}\text { Economic Status } \\
\text { Low class } \\
\text { Middle class } \\
\text { High Class }\end{array}$ & $\begin{array}{l}3 \\
56 \\
1\end{array}$ & $\begin{array}{l}5.0 \\
93.3 \\
1.7\end{array}$ \\
\hline 7 & \begin{tabular}{l}
\multicolumn{1}{c}{ Marital duration(in yrs) } \\
$1-3$ \\
$4-6$ \\
$7-9$ \\
$10-12$ \\
$>12$
\end{tabular} & $\begin{array}{l}16 \\
28 \\
13 \\
2 \\
1\end{array}$ & $\begin{array}{l}26.7 \\
46.7 \\
21.7 \\
3.3 \\
1.7\end{array}$ \\
\hline 8 & $\begin{array}{l}\text { Menstrual pattern } \\
\text { Regular } \\
\text { Irregular }\end{array}$ & $\begin{array}{l}47 \\
13\end{array}$ & $\begin{array}{l}78.3 \\
21.7\end{array}$ \\
\hline
\end{tabular}

$\mathrm{n}=60$

Table 2: Association between BMI scale with selected demographic variables

\begin{tabular}{lllll}
\multicolumn{5}{c}{$\mathrm{n}=60$} \\
\hline S1. & & Calculated & & \\
No. & Demographic variables & value & P value & Inference \\
\hline 1 & Age Group & 2.160 & $\mathrm{p}>0.05$ & No Association \\
2 & Religion & 2.858 & $\mathrm{p}>0.05$ & No Association \\
3 & Type of food & 0.230 & $\mathrm{p}>0.05$ & No Association \\
4 & Educational status & 5.683 & $\mathrm{p}>0.05$ & No Association \\
5 & Occupational status & 1.828 & $\mathrm{p}>0.05$ & No Association \\
6 & Economic status & 0.610 & $\mathrm{p}>0.05$ & No Association \\
7 & Marital Duration........ & 9.997 & $\mathrm{p}>0.05$ & No Association \\
8 & Menstrual Pattern & 0.249 & $\mathrm{p}>0.05$ & No Association \\
\hline
\end{tabular}

\section{Discussion}

In the present study three forth of women were in the age group of 25-32. Maximum of the women were in the category of non-vegetarians. Three by five women were four to six years marital duration. Three by forth of the women had regular menstrual cycle whereas remaining had irregularity in the menstrual cycle. The Body Mass Index showed as few women (10\%) were under weight, some $(8.3 \%)$ women were Obese and Most (26.7\%) of the women had over weight whereas (55\%) women had normal body weight. A similar study was conducted in Australia with the purpose of identify the factors associated with infertility among general population of women $(n=9,145)$. The study was conducted for women at the age group of 28-33 years ${ }^{22}$. The pilot study conducted in Australia for eighteen young infertile women. The result of the study revealed that dietary intake was found to be negatively correlated with the interpersonal sensitivity ${ }^{13}$.

Analysis of the association between obesity (BMI scores) and selected demographic variables exposed that there is no association between the BMI Scores and selected variables such as age, type of food, economic status, marital duration, menstrual pattern $(\mathrm{p}>0.05)$. The findings is supported by the findings of a study conducted in New York for 290 infertile women which also divulged that there is no association of infertility and selected demographic variables like menstrual pattern, duration and race ${ }^{24}$.

\section{Conclusion}


The findings of the study illustrated that few women were obese and most of the women had overweight. There was no significant association between BMI scores and demographic variables. It can be concluded that infertile women are having obesity and overweight. Therefore women should maintain their weight and decrease the overweight and obesity to enhance fertility, and lead to successful full term pregnancies. Information regarding effect of overweight in fertility and ways to maintain their fertility will help to create the awareness among the women to enhance their fertility. Hence, nurses can explain and motivate the women to follow the healthy life styles and reduce their obesity which in turn will reduce the burden of infertility and enhance its management. In addition to this, further researches should be conducted to cover other areas and different part of the country to find out the association between obesity and infertility.

\section{Acknowledgement}

We owe a great deal of gratitude to management of Yenepoya University and Santhathi Infertility Clinic, Mangalore for providing the permission to conduct the study. Our special thanks go to all the participants of the study for their cooperation. We are grateful to all who have supported and motivated for the study and publication.

[1] UNFPA. Prevention and management of infertility in primary health care settings. New Delhi, India. Available from url:india.unfpa.org/drive/fertility.pdf

[2] [WHO. Sexual and reproductive health: Global prevalence of infertility, infecundity and childlessness [online]. 2012 Dec. Available from: www.who.int/reproductivehealth/topics/infertility/burden/en/

[3] Science News from Universities. Global rates of infertility remain unchanged over past 2 decades. Journals, and other research organizations Dec. 18, 2010

[4] Dey S. Infertility rises at alaraming pace in India. English news. 2010 July. 15:04:38.

[5] Kocelak P, Chudek J, Naworska B, Bak-Sosnowska M, Kotlarz D, Mazurek N, et.al. Psychological disturbances and quality of life in obese and infertile women and men. International Journal of endocrinology. 2012; 2012(2012): 14.

[6] Paul C, Karl K, Alexandra H, Freeman, Jeffrey D, Arthur A, Reingold. Prevalence \& correlates of primary infertility among young women in Mysore, India. Indian J Med Res 2011 Oct;134(4):440-6.

[7] Wilkes S, Murdoch A. Obesity and female fertility: a primary care perspective. J Fam Plann Reprod Health Care. 2009 Jul; 35(3):181-5.

[8] Tapia Z. Does obesity cause infertility? Times wellness. 20126 Jan. Available from www.timeswellness.com/article/.../Doesobesity-cause-infertility.html.

[9] Pasquali R, Patton L, Gambineri L. Obesity and infertility. Curr Opin Endocrinol Diabetes Obes 2007 Dec;14(6):482-7.

[10] Gaur A. Obesity in females leads to infertility, affects ovary functioning: Study. 2013 Mar 24, 09.03 PM IST

[11] Mittal S, Dhaliwal L, Sharma S, Chauhan S Garg S, Neeta S. Infertility, Obstetrics and Gynaecology International 2012;2012:508276.

[12] Mayra M. Does obesity really cause infertility?. SiOWfa12: Science in our world: Certainty and controversy. 2012 Oct 18. 5:52 pm. Available from: www.personal.psu.edu/afr 3/blogs/siowfa12/.../weight-lossmore-sex.html.

[13] Colombo O, Pinelli G, Comelli M, Marchetti P, Sieri S, Brighenti F et. al. Nutr J 2009 Nov 10;8:53.

[14] Buyuk E, Seifer DB, Illions E, Grazi RV, Lieman H. Fertil Steril 2011 Jun;95(7):2364-8 